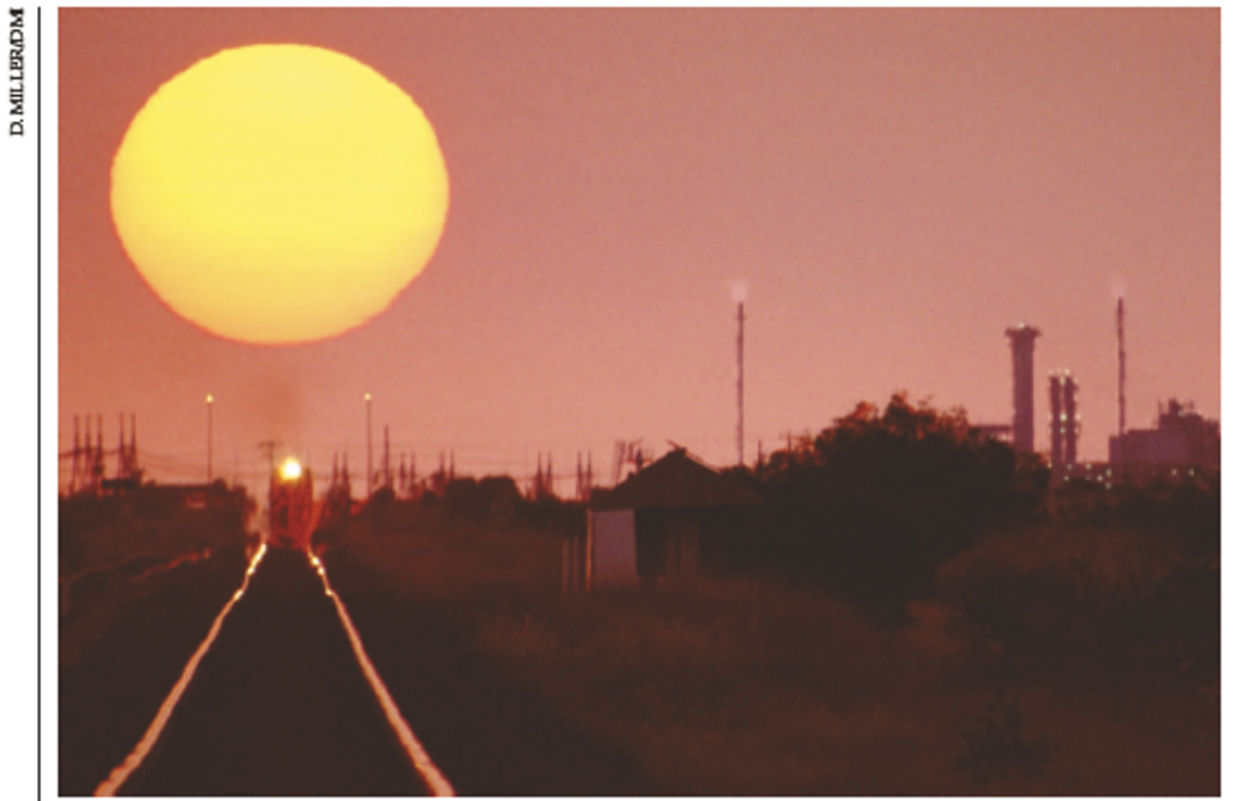

Sun block: 'global dimming' caused by air pollution may have been masking the greenhouse effect.

\title{
Cleaner skies leave global warming forecasts uncertain
}

Quirin Schiermeier, Munich

Finally, some good news about the state of our planet. Studies of the amount of sunlight making it through the atmosphere suggest that our air is getting cleaner, thanks to reduced industrial emissions and the use of particulate filters.

But there's a nasty sting in the tail. Scientists are concerned that aerosols and dust in the air may have been shielding us from the worst of global warming. They don't know how extra solar radiation will affect future temperatures.

A downward trend in the amount of sunlight reaching the planet's surface, known as 'global dimming', has been noticed since measurements began in the late $1950 \mathrm{~s}$, but consensus that it was a global phenomenon was reached only last year (see Nature doi:10.1038/news040517-7; 2004). Many scientists have been reluctant to discuss the effect, fearing it would be used as an excuse to ignore the consequences of global warming.

They don't need to worry about that any more. Two studies, reported in Science, conclude that since 1990 the dimming has been replaced by brightening (M. Wild et al. Science 308, 847-850;2005 and R.T. Pinker,B. Zhang andE.G.Dutton Science 308, 850-854; 2005). Ithas taken years to collect enough data for a statistically significant analysis, says Martin Wild, an atmospheric scientist at the Swiss FederalInstituteof Technologyin Zurich.

Wild and an international team of scientists analysed data from hundreds of ground stations around the world. They found that the amount of radiation reaching Earth's surface fell by 4-6\% between 1960 and 1990 , but that the trend has since reversed nearly everywhere - although the total amount of radiation has not yet reached 1960 levels.

The result is backed up by a second study, led by Rachel Pinker from the University of Maryland, College Park, which infers a similar, albeit smaller, trend from satellite data.

"The good news is that the atmosphere has become cleaner and more transparent, says Andreas Macke, a meteorologist at the Leibniz Institute of Marine Sciences in Kiel, Germany. The collapse of communist economies in the late 1980 s and the subsequent decrease in industrial pollutants released in the area was probably a major factor.

Wild and his team did detect continued dimming in some highly polluted areas, such as India, where vast clouds of smog from burning fossil fuels and wildfires darken the sky for long periods each year. But there was a brightening trend in China, despite the country's booming, fossil-fuel-intensive industry. "I am surprised," says Wild, adding that he can only speculate that the use of clean-air technologies in China may be more widespread and efficient than previously thought.

The question now is how the trend towards cleaner air will affect global temperatures."It is dear that thegreenhouse effect has been partly masked in the past by air pollution," says Macke.

Wild is investigating just how much was masked. He has yet to publish his results but he estimates that, until 1990, air pollution protected us from at least $50 \%$ of the warming that would have otherwise occurred.
Wanted: scientists to shape Europe's future research policy

Alison Abbott, Munich

Twenty people are set to become the most influential scientists in European basic research policy - at least for a while. They will form the governing council of the planned European Research Council (ERC), and they are due to be named next month.

The ERC will be the first pan-European research funding agency. Although part of the European Commission's next Framework programme for research (FP7), which begins late next year, it will be run by the academic community largely independently of the commission.

The first ERC governing council will be particularly powerful, as its remit will be to shape the broad programmes under which the European research community will apply for project funding. The commission has proposed that the ERC budget should average a hefty $€ 1.5$ billion (US\$1.9 billion) per year. But even if the European Parliament and the Council of Ministers agree to this generous funding, massive oversubscription is feared. So the council may try to limit demand by, for example, earmarking funds for certain sectors, such as young scientists. It will also set up evaluation and peer-review systems.

Members of the council are being selected by a panel of five academics chaired by Chris Patten, chancellor of Oxford and Newcastle universities. The panel was appointed by the European Commission in January and has since invited nominations from various European bodies involved in research, including national academies, research funding agencies, industry and universities. Despite requesting restraint, the panel has received well over 200 suggestions.

The final list will be designed to provide maximum credibility and authority, says the panel, and will be broadly representative of disciplines and types of research.

Gender and geography will also be taken into account, but panel members defend their commitment to idealism. "The ERC is about frontier research and excellence," says panel member and 1991 Nobel laureate Erwin Neher of the Max Planck Institute for Biophysical Chemistry in Göttingen. "The coundl needs to be credible in Europe, so balance is necessary - but there will be no question of geographical distribution of funds, or fuste retour." 